\title{
Papers
}

\section{Breast feeding and obesity: cross sectional study}

\author{
Rüdiger von Kries, Berthold Koletzko, Thorsten Sauerwald, Erika von Mutius, Dietmar Barnert, \\ Veit Grunert, Hubertus von Voss
}

\begin{abstract}
Objective To assess the impact of breast feeding on the risk of obesity and risk of being overweight in children at the time of entry to school.

Design Cross sectional survey

Setting Bavaria, southern Germany.

Methods Routine data were collected on the height and weight of 134577 children participating in the obligatory health examination at the time of school entry in Bavaria. In a subsample of 13345 children, early feeding, diet, and lifestyle factors were assessed using responses to a questionnaire completed by parents.

Subjects 9357 children aged 5 and 6 who had

German nationality.

Main outcome measures Being overweight was defined as having a body mass index above the 90th centile and obesity was defined as body mass index above the 97th centile of all enrolled German children. Exclusive breast feeding was defined as the child being fed no food other than breast milk. Results The prevalence of obesity in children who had never been breast fed was $4.5 \%$ as compared with $2.8 \%$ in breastfed children. A clear dose-response effect was identified for the duration of breast feeding on the prevalence of obesity: the prevalence was 3.8\% for 2 months of exclusive breast feeding, 2.3\% for 3-5 months, $1.7 \%$ for $6-12$ months, and $0.8 \%$ for more than 12 months. Similar relations were found with the prevalence of being overweight. The protective effect of breast feeding was not attributable to differences in social class or lifestyle. After adjusting for potential confounding factors, breast feeding remained a significant protective factor against the development of obesity (odds ratio $0.75,95 \%$ CI 0.57 to 0.98 ) and being overweight $(0.79,0.68$ to 0.93$)$.

Conclusions In industrialised countries promoting prolonged breast feeding may help decrease the prevalence of obesity in childhood. Since obese children have a high risk of becoming obese adults, such preventive measures may eventually result in a reduction in the prevalence of cardiovascular diseases and other diseases related to obesity.
\end{abstract}

\section{Introduction}

In industrialised countries obesity and being overweight are the most frequent nutritional disorders in children and adolescents, and there is a continuing increase in their prevalence. ${ }^{1}$ Overweight children have a high risk of being overweight in adulthood ${ }^{2-4}$ and therefore are also at risk from the associated health complications such as hypertension and coronary heart disease. ${ }^{5}$ Since therapeutic interventions aimed at encouraging weight loss in obese children are costly and have long term success rates that are less than satisfactory, ${ }^{6}$ the identification of strategies for the effective prevention of obesity is particularly attractive.

Simple strategies without potential side effects are the most appealing. Breast feeding would fulfil these criteria. However, the impact of breast feeding on obesity has only been studied in comparatively small cohorts. $^{7-9}$ These small studies failed to find a protective effect possibly due to a lack of statistical power, whereas a protective effect has been reported in a Canadian cross sectional study of 1320 adolescents born in the late $1960 \mathrm{~s} .{ }^{10}$ The rates of breast feeding were low in Canada at that time, and lifestyles in industrialised countries have changed considerably over the past three decades. We have therefore studied the impact of breast feeding on the prevalence of being overweight or obese in children born in the early 1990s.

\section{Subjects and methods}

\section{Study population and data sources}

The 1997 obligatory health examination before school entry evaluated 134577 children in Bavaria, southern Germany. At the examination, the parents of 13345 children seen in two rural regions were asked to complete a questionnaire about risk factors for atopic diseases. ${ }^{11}$ Data collected by this questionnaire were linked with the data from the school health examination. Our analysis was confined to children aged 5 and 6 who had German nationality.

The children's height and weight were measured as part of the routine examination. Body mass index was calculated as weight $(\mathrm{kg}) /\left(\right.$ height $\left.(\mathrm{m})^{2}\right)$. The age specific and sex specific distribution of the body mass index among all children with German nationality in Bavaria, which had been investigated during the 1997 school health examination, was used as the reference for being overweight (defined as body mass index above the 90th centile) or obese (defined as body mass index above the 97 th centile) because these centiles were higher than other European reference values. ${ }^{12}$

\author{
Institute for Social \\ Paediatrics and \\ Adolescent \\ Medicine, Ludwig \\ Maximilians \\ University, \\ Heiglhofstr 63 \\ D-81377 Munich, \\ Germany \\ Rüdiger von Kries, \\ professor of \\ paediatrics \\ Dietmar Barnert, \\ statistician \\ Veit Grunert, \\ statistician \\ Hubertus von Voss, \\ professor of \\ paediatrics \\ Dr von \\ Haunersches \\ Kinderspital, \\ Ludwig \\ Maximilians \\ University, \\ Lindwurmstr 4, \\ D-80337 Munich \\ Berthold Koletzko, \\ professor of \\ paediatrics \\ Thorsten \\ Sauerwald, \\ senior house officer \\ Erika von Mutius, \\ reader in paediatrics \\ Correspondence to: \\ $\mathrm{R}$ von Kries \\ ag.epi@lrz. \\ uni-muenchen.de
}

BMJ 1999;319:147-50 
Table 1 Duration of breast feeding and prevalence (95\% confidence interval) of being overweight (body mass index above the 90th centile) or obese (body mass index above the 97th centile) among 5 and 6 year olds living in rural Bavaria

\begin{tabular}{lcc} 
& \multicolumn{2}{c}{ Prevalence (\%) of: } \\
\cline { 2 - 3 } Duration of breast feeding & Being overweight & Being obese \\
\hline Never breast fed $(n=4022)$ & $12.6(12.4$ to 12.9$)$ & $4.5(4.4$ to 4.6$)$ \\
\hline Ever breast fed $\left(n=5184^{*}\right)$ & $9.2(9.0$ to 9.3$)$ & $2.8(2.7$ to 2.8$)$ \\
\hline Exclusively breast fed for: & & \\
\hline$\leqslant 2$ months $(n=2084)$ & $11.1(10.6$ to 11.6$)$ & $3.8(3.6$ to 4.0$)$ \\
\hline $3-5$ months $(n=2052)$ & $8.4(8.1$ to 8.8$)$ & $2.3(2.2$ to 2.4$)$ \\
\hline $6-12$ months $(n=863)$ & $6.8(6.1$ to 7.6$)$ & $1.7(1.6$ to 1.9$)$ \\
\hline$>12$ months $(n=121)$ & $5.0(1.1$ to 8.8$)$ & $0.8(0.2$ to 1.5$)$ \\
\hline
\end{tabular}

*Duration of breast feeding was not reported for 64 children who had ever been breast fed.

\section{Questionnaire}

Parents were asked: "Was your child breast fed?" If they answered yes they were then asked: "For how long was your child exclusively breast fed: (a) 2 months or less, (b) 3 to 5 months, (c) 6 to 12 months or (d) more than a year?" Exclusive breast feeding was defined as the child being fed no food other than breast milk.

To assess potential confounders additional questions were asked about the number of older siblings the child had and the parents' ages, the child's health (for example, was the child born prematurely or at low birth weight?), early feeding (for example, when solid foods were introduced), and the actual frequency of eating selected foods. The highest level of education attained by either parent was used as a marker for social class.

\section{Statistical analyses}

The prevalences of overweight and obese children were calculated according to the duration of breast feeding. The appropriate $\chi^{2}$ tests were used to compare several items in breastfed and non-breastfed children and their association with the child being overweight or obese. Logistic regression models were used to assess the impact of variables that were significantly associated $(\mathrm{P}<0.05)$ with both breast feeding and being overweight or obese. Confounding was assumed to have occurred if the odds ratio changed by $\geqslant 10 \%$. Confounders and independent risk factors were included in the final logistic regression model. All calculations were carried out with the SAS software package, version 6.12.

\section{Results}

The overall response rate to the questionnaire was 76.7\% (10 240/13 345) Parents whose children had been examined before 1 February did not receive questionnaires and were classed as non-responders. We could not differentiate between true non-responders and children whose parents had not been given questionnaires so both were included as nonresponders for calculations of well baby visits and immunisations because similar results had been obtained when these calculations were confined to those offices where all parents had received questionnaires.

A total of 9357 questionnaires were completed for 5 and 6 year old German children. Information on breast feeding and its duration was available for 9206 children. A total of 4022 children had never been breast fed and 5184 had ever been breast fed. The duration of breast feeding was not reported for 64 children.

Responders were more likely than non-responders to have attended all well baby visits $(70.6 \%$ (6524/ 9238) v 64\% (4511/7044)) and to have had their children vaccinated against measles and Haemophilus influenzae type b $(72.3 \% \quad(6764 / 9357) \quad v \quad 64 \%$ (4596/7178)), but mean body mass index and the 90th and 97th centiles for body mass index were similar between the groups (mean $15.36 v 15.34$; 90th centile $17.70 v 17.75$; and 97 th centile 20.12 v 20.07).

There was a clear dose dependent effect of the duration of breast feeding on the prevalence of being overweight or obese in children at the time of entry to school (table 1). Similar effects of the duration of breast feeding on the prevalence of being overweight or obese were observed when different definitions of being overweight or obese were used (that is, above the 90th centile or above the 97 th centile for weight; above $110 \%$ or above $120 \%$ of the median weight for height categories in the total population (data not shown)).

Several indicators of the family's lifestyle and make up (for example, whether the child had his or her own bedroom, the amount of time spent playing outside in winter and summer, whether the mother smoked during

Table 2 Prevalence of independent risk factors associated with breast feeding and being overweight or obese in 5 and 6 year old children in rural Bavaria

\begin{tabular}{|c|c|c|c|c|}
\hline & Preval & nce (\%) & Odds $\mathrm{r}$ & ) for: \\
\hline & $\begin{array}{c}\text { Non-breast fed } \\
\text { children }(\mathrm{n}=4022)\end{array}$ & $\begin{array}{l}\text { Breast fed children } \\
\quad(n=5184)\end{array}$ & Being overweight & Being obese \\
\hline High level of parental education ( $\geqslant 10$ years) ${ }^{\star}$ & 41.4 & 66.7 & 0.77 (0.67 to 0.89$)$ & $0.62(0.49$ to 0.79$)$ \\
\hline Maternal smoking during pregnancy & 12.8 & 4.2 & 1.51 (1.20 to 1.89$)$ & 1.82 (1.28 to 2.58$)$ \\
\hline Prematurity & 13.8 & 9.0 & 0.78 (0.62 to 0.98$)$ & 0.69 (0.46 to 1.03$)$ \\
\hline Birth weight $<2500 \mathrm{~g}$ & 10.4 & 6.6 & 0.69 (0.48 to 0.84$)$ & 0.78 (0.54 to 1.10$)$ \\
\hline Own bedroom & 45.6 & 54.4 & 1.19 (1.03 to 1.37$)$ & $1.22(0.96$ to 1.56$)$ \\
\hline Consumes margarine $\geqslant 3$ times/week & 35.3 & 32.4 & $1.22(1.05$ to 1.41$)$ & 1.21 (0.94 to 1.56$)$ \\
\hline Consumes butter $\geqslant 3$ times/week & 60.5 & 69.2 & 0.73 (0.63 to 0.83$)$ & 0.70 (0.56 to 0.88$)$ \\
\hline Consumes full fat milk $\geqslant 3$ times/week & 50.8 & 59.6 & 0.69 (0.60 to 0.80$)$ & 0.54 (0.42 to 0.68$)$ \\
\hline Consumes low fat milk $\geqslant 3$ times/week & 31.9 & 28.8 & 1.72 (1.49 to 1.99$)$ & 1.77 (1.38 to 2.25$)$ \\
\hline Consumes full fat quark or yogurt $\geqslant 3$ times/week & 28.8 & 36.1 & 0.66 (0.56 to 0.78$)$ & $0.52(0.38$ to 0.70$)$ \\
\hline Consumes low fat quark or yogurt $\geqslant 3$ times/week & 25.9 & 23.8 & 1.42 (1.22 to 1.66$)$ & $1.32(1.02$ to 1.71$)$ \\
\hline Consumes whipped cream $\geqslant 1$ time/week & 18.6 & 24.7 & 0.65 (0.54 to 0.79$)$ & 0.58 (0.41 to 0.81$)$ \\
\hline Consumes breakfast cereals $\geqslant 3$ times/week & $25.6 \%$ & 35.3 & 0.80 (0.68 to 0.93$)$ & 0.76 (0.58 to 0.99$)$ \\
\hline Consumes sweet desserts $\geqslant 3$ times/week & $54.4 \%$ & 57.8 & $0.84(0.74$ to 0.97$)$ & $0.82(0.66$ to 1.03$)$ \\
\hline
\end{tabular}

${ }^{\star}$ This variable changed the odds ratio for breast feeding and being overweight or obese by at least $10 \%$, so confounding was assumed to have occurred. 
Table 3 Odds ratios for independent risk factors associated with being overweight or obese in the final logistic regression model for 92065 and 6 year old children in rural Bavaria

\begin{tabular}{|c|c|c|}
\hline & \multicolumn{2}{|c|}{ Odds ratio $(90 \% \mathrm{CI})$ for: } \\
\hline & Being overweight & Being obese \\
\hline Breast feeding & 0.79 (0.68 to 0.93$)$ & 0.75 (0.57 to 0.98$)$ \\
\hline $\begin{array}{l}\text { High level of parental education } \\
(\geqslant 10 \text { years })^{*}\end{array}$ & 0.81 (0.70 to 0.95$)$ & 0.75 (0.58 to 0.98$)$ \\
\hline $\begin{array}{l}\text { Maternal smoking during } \\
\text { pregnancy }\end{array}$ & 1.52 (1.81 to 1.95) & 1.85 (1.26 to 2.71$)$ \\
\hline Birth weight <2500 g & 0.68 (0.53 to 0.88$)$ & 0.81 (0.54 to 1.20$)$ \\
\hline Own bedroom & 1.24 (1.05 to 1.46$)$ & 1.20 (0.91 to 1.59$)$ \\
\hline $\begin{array}{l}\text { Consumes butter } \\
\geqslant 3 \text { times/week }\end{array}$ & $0.72(0.62$ to 0.84$)$ & $0.69(0.54$ to 0.90$)$ \\
\hline
\end{tabular}

pregnancy, the number of older siblings, and the age of the parents), early feeding habits, and the frequency of the consumption of several products in the child's diet differed significantly between children who had been breast fed and those who had not. The prevalence of variables which were also significantly associated with a child being overweight or obese and which were independent risk factors in a logistic regression model with breast feeding is shown in table 2.

Higher levels of parental education ( $\geqslant 10$ years), premature birth, and low birth weight were inversely associated with being overweight or obese, whereas maternal smoking during pregnancy and the child having his or her own bedroom were positively correlated. Full fat milk products and sweet desserts were less frequently consumed by overweight children, and the consumption of low fat milk products was higher. Overweight children also ate less butter and breakfast cereals than children who were not overweight.

The level of parental education was the only factor that accounted for a shift of the odds ratio towards unity by at least $10 \%$ which related breast feeding to being overweight or obese. In the final logistic regression, which estimated the influence of breast feeding on the dependent variable of being overweight or being obese, the independent risk factors for maternal smoking, low birth weight, own bedroom, and frequent consumption of butter were included in addition to the confounding variable of higher level of parental education (table 3).

Crude and adjusted odds ratios for the dose dependent impact of breast feeding on being overweight or obese are shown in table 4 . In children who had been breast fed for at least 6 months or more the risks of being overweight or obese were reduced by $>30 \%$ and $>40 \%$, respectively.

\section{Discussion}

Epidemiological evidence for reduced risk

To our knowledge this is the largest epidemiological study on the impact of breast feeding on the risk of school age children being overweight or obese. The most remarkable finding is a consistent, protective, and dose dependent effect of breast feeding on different definitions of obesity or being overweight. Some relevant questions, however, were not asked in our questionnaire because it had been designed originally to identify atopy. The impact of breast feeding on body mass increase ("catch up growth") in low birthweight infants, which is associated with an additional risk of coronary heart disease,$^{13}$ could therefore not be analysed. A positive family history of being overweight is an important indicator of the genetic risk for obesity and being overweight, ${ }^{9} 10$ although it is not a confounder of the association between breast feeding and obesity or being overweight as found in a previous study. ${ }^{10}$

Breast feeding was associated with family make up and lifestyle, premature birth, low birth weight, and early and current diet. There was an inverse relation between the consumption of butter and margarine and consumption of low fat and full fat dairy products. The inverse relation between the actual consumption of full fat dairy products and obesity or being overweight probably reflects avoidance of these products by children who are overweight. Because of these strong relations and the apparent reverse causation with regard to full fat dairy products, only low birth weight and the consumption of butter were added to the final logistic regression model.

The protective effects of a higher level of parental education and low birth weight accord with the results of other studies. ${ }^{910}{ }^{13}$ Family income or social class might be better indicators of socioeconomic status. Unfortunately, in Germany there is no accepted equivalent to the British categories of social class, and respondents to written questionnaires are reluctant to report income.

A similar dose dependent reduction in the risk of being overweight or obese as associated with breast feeding was observed in Canadian adolescents born in the $1960 \mathrm{~s}^{10}$ Only $18.5 \%$ of these children had been breast fed exclusively as compared with $56 \%$ of those born in Bavaria in the 1990s; this suggests that mothers with different sociodemographic characteristics have chosen to breast feed their children in Bavaria now. If this dose dependent protective effect had been caused by lifestyle factors associated with breast feeding, similar confounding factors should have been operative during different times in different societies. These factors would also have to be closely related to the duration of breast

Table 4 Crude and adjusted odds ratios (95\% confidence intervals) of the dose dependent impact of breast feeding on being overweight or obese in children aged 5 or 6 in rural Bavaria

\begin{tabular}{|c|c|c|c|c|}
\hline & \multicolumn{2}{|c|}{ Being overweight } & \multicolumn{2}{|c|}{ Being obese } \\
\hline & Adjusted odds ratio* & Crude odds ratio & Adjusted odds ratio* & Crude odds ratio \\
\hline \multicolumn{5}{|l|}{ Exclusively breast fed for: } \\
\hline$\leqslant 2$ months $(\mathrm{n}=2084)$ & 0.89 (0.73 to 1.07$)$ & 0.87 (0.74 to 1.02$)$ & $0.90(0.65$ to 1.24$)$ & 0.84 (0.64 to 1.10$)$ \\
\hline 3-5 months $(n=2052)$ & 0.87 (0.72 to 1.05) & $0.64(0.53$ to 0.76$)$ & $0.65(0.44$ to 0.95$)$ & $0.50(0.36$ to 0.69$)$ \\
\hline $6-12$ months $(n=863)$ & 0.67 (0.49 to 0.91$)$ & 0.51 (0.38 to 0.67$)$ & 0.57 (0.33 to 0.99$)$ & $0.38(0.22$ to 0.64$)$ \\
\hline$>12$ months $(n=121)$ & $0.43(0.17$ to 1.07$)$ & 0.36 (0.16 to 0.82$)$ & $0.28(0.04$ to 2.04$)$ & 0.18 (0.03 to 1.28$)$ \\
\hline Ever breast fed $(n=5184)$ & $0.79(0.68$ to 0.93$)$ & $0.70(0.61$ to 0.80$)$ & 0.75 (0.57 to 0.98$)$ & 0.61 (0.50 to 0.76$)$ \\
\hline
\end{tabular}

${ }^{*}$ Odds ratios adjusted for level of parental education, maternal smoking during pregnancy, low birth weight, own bedroom, and frequent consumption of butter. 


\section{Key messages}

- Obesity is the most frequent nutritional disorder in children, and is an important risk factor for cardiovascular disease in adulthood

- Preventing obesity in children should be a useful strategy in preventing later heart disease because weight loss interventions in obese children are costly and rarely successful

- Data from a cross sectional study in Bavaria suggest that the risk of obesity in children at the time of school entry can be reduced by breast feeding: a 35\% reduction occurs if children are breastfed for 3 to 5 months

- Preventing obesity and its consequences may be an important argument in the drive to encourage breast feeding in industrialised countries
Contributors: RvK coordinated and designed the study, analysed the data, wrote the paper and is guarantor for the paper. $\mathrm{BK}$ had the original idea for the study and wrote the nutritional aspects of the discussion. TS contributed to the discussion of the results. EvM designed the questionnaire for the study of atopy and made important suggestions about the epidemiological and statistical analyses and the writing of the paper. DB managed the dataset on all children enrolled in the 1997 school entry health examination. VG checked all statistical procedures and calculations in SAS, and is also a guarantor for the study. HvV initiated the research project in collaboration with the public health offices in Bavaria.

Funding: Bayrisches Staatsministrium für Arbeit und Sozialordnung, Familie, Frauen und Gesundheit and Stiftung Kindergesundheit.

Competing interests: None declared.

1 Freedman DS, Srinivasan SR, Valdez RA, Williamson DF, Berenson GS. Secular increases in relative weight and adiposity among children over two decades: the Bogalusa Heart Study. Pediatrics 1997;99:420-6.

2 Charney E, Goodman HC, McBride M, Lyon B, Pratt R. Childhood antecedents of adult obesity: do chubby infants become obese adults? N Engl J Med 1976;295:6-9.

feeding for each child in both populations to explain the dose effect related to the duration of breast feeding which was observed both in the Canadian study and our study. The protective effect of breast feeding therefore is more likely to be related to the properties of breast milk or the breastfeeding process than to lifestyle factors associated with breast feeding.

\section{Biological plausibility}

In addition, it is plausible that breast feeding might indeed have a programming effect in preventing obesity or becoming overweight in later life. Lucas and colleagues found significantly higher plasma concentrations of insulin in infants who had been bottle fed than in infants who had been breast fed; these higher concentrations would be expected to stimulate fat deposition and the early development of adipocytes. ${ }^{145}$ Breast milk also contains bioactive factors which may modulate epidermal growth factor and tumour necrosis factor $\alpha$, both of which are known to inhibit adipocyte differentiation in vitro. ${ }^{16}$ The amount of energy metabolised and the protein intake of breastfed children is considerably lower than previously assumed and significantly below the intake of infants who are fed formulas. ${ }^{18}{ }^{19}$ In longitudinal studies a significant relation was found between dietary protein intake at the age of 10 months and later body mass index and the distribution of body fat ${ }^{20-22}$; this suggests that a high intake of protein in early childhood might increase the risk of obesity later. Indeed, in animal studies the availability of protein during fetal and postnatal development was found to have long term effects on the metabolic programming of glucose metabolism and body composition in adult life..$^{23-25}$

\section{Conclusion}

Prolonged exclusive breast feeding reduced the risk of being obese or overweight among school age children in Bavaria who were born in the early 1990s. This effect is more likely to be related to the composition of breast milk than to lifestyle factors associated with breast feeding. Preventing childhood obesity and its consequences may be an important argument in the drive to encourage breast feeding in industrialised countries.

We thank all parents for answering the questionnaires, the doctors and their assistants in the public health offices for distributing and collecting the questionnaires, for encouraging the parents to answer the questionnaires and for measuring and recording the weight and height of all children attending the school entrance health examination
3 Stark O, Atkins E, Wolff OH, Douglas JW. Longitudinal study of obesity in the National Survey of Health and Development. BMJ 1981;283:13-7.

4 Abraham S, Collins G, Nordsieck M. Relationship of childhood weight status to morbidity in adults. Health Services and Mental Health Administration Health Report 1971;86:273-84.

5 Power C, Lake JK, Cole TJ. Measurement and long-term health risks of child and adolescent fatness. Int J Obes Relat Metab Disord 1997;21:507-26.

6 Canadian Task Force on the Periodic Health Examination. Periodic health examination, 1994 update. I. Obesity in childhood. Can Med Assoc J 1994;150:871-9.

7 Wilkinson PW, Parkin JM, Pearlson J, Philips PR, Sykes P. Obesity in childhood: a community study in Newcastle upon Tyne. Lancet 1977;i:350-2.

8 Baranowski T, Bryan GT, Rassin DK, Harrison JA, Henske JC. Ethnicity, infant-feeding practices, and childhood adiposity. J Dev Behav Pediatr 1990;11:234-9.

9 Poskitt EM, Cole TJ. Nature, nurture, and childhood overweight. BMJ 1978;i:603-5.

10 Kramer MS. Do breast-feeding and delayed introduction of solid foods protect against subsequent obesity? J Pediatr 1981;98:883-7.

11 Von Ehrenstein O, von Mutius E, Illi S, Böhm O, Hachmeister A, von Kries R. Reduced risk for atopic diseases in farmers' children. Clin Exp Allergy 1999 (in press.)

12 Rolland-Cachera MF, Cole TJ, Sempe M, Tichet J, Rossignol C, Charraud A. Body mass index variations: centiles from birth to 87 years. Eur J Clin Nutr 1991;45:13-21.

13 Eriksson JG, Forsen T, Tuomilehto J, Winter PD, Osmond C, Barker DJP. Catch-up growth in childhood and death from coronary heart disease: longitudinal study. BMJ 1999;318:427-31.

14 Lucas A, Sarson DL, Blackburn AM, Adrian TE, Aynsley-Green A, Bloom SR. Breast vs bottle: endocrine responses are different with formula feeding. Lancet 1980;1:1267-9.

15 Lucas A, Boyes S, Bloom SR, Aynsley-Green A. Metabolic and endocrine responses to a milk feed in six-day-old term infants: differences between breast and cow's milk formula feeding. Acta Paediatr Scand 1981;70:195200 .

16 Hauner H, Rohrig K, Petruschke T. Effects of epidermal growth factor (EGF), platelet-derived growth factor (PDGF) and fibroblast growth factor (FGF) on human adipocyte development and function. Eur J Clin

17 Petruschke T, Rohrig K, Hauner H. Transforming growth factor beta (TGF-beta) inhibits the differentiation of human adipocyte precursor cells in primary culture. Int J Obes Relat Metab Disord 1994:18:532-6.

18 Whitehead RG. For how long is exclusive breast-feeding adequate to satisfy the dietary energy needs of the average young baby? Pediatr Res $1995 ; 37: 239-43$

19 Heinig MJ, Nommsen LA, Peerson JM, Lonnerdal B, Dewey KG. Energy and protein intakes of breast-fed and formula-fed infants during the first year of life and their association with growth velocity: the DARLING Study. Am J Clin Nutr 1993;58:152-61.

20 Rolland-Cachera MF, Deheeger M, Akrout M, Bellisle F. Influence of macronutrients on adiposity development: a follow up study of nutrition and growth from 10 months to 8 years of age. Int J Obes Relat Metab Disord 1995; $19: 573-8$

21 Rolland-Cachera MF, Deheeger M, Bellisle F. Nutrient balance and android body fat distribution: why not a role for protein? [letter; comment]. Am J Clin Nutr 1996;64:663-4.

22 Deheeger M, Akrout M, Bellisle F, Rossignol C, Rolland-Cachera MF. Individual patterns of food intake development in children: a 10 months to 8 years of age follow-up study of nutrition and growth. Physiol Behav 1996;59:403-7.

23 Burns SP, Desai M, Cohen RD, Hales CN, Iles RA, Germain JP, et al. Gluconeogenesis, glucose handling, and structural changes in livers of the adult offspring of rats partially deprived of protein during pregnancy and lactation. J Clin Invest 1997;100:1768-74.

24 Desai M, Byrne CD, Zhang J, Petry CJ, Lucas A, Hales CN. Programming of hepatic insulin-sensitive enzymes in offspring of rat dams fed a protein-restricted diet. Am J Physiol 1997;272:G1083-90.

25 Desai M, Hales CN. Role of fetal and infant growth in programming metabolism in later life. Biol Rev Camb Philos Soc 1997;72:329-48. (Accepted 4 May 1999) Invest 1995;25:90-6. 